\title{
A GESTÃO DE STAKEHOLDERS EM GESTÃO DE PROJETOS
}

\section{MANAGEMENT OF STAKEHOLDERS IN PROJECT MANAGEMENT}

\section{Greice de Bem Noro}

Doutoranda em Administração pela Universidad Nacional de Missiones em Posadas, AR

Professora e Coordenadora de Extensão do Curso de Administração do Centro Universitário Franciscano - UNIFRA.

E-mail: gbgreice@gmail.com (Brasil) 


\title{
A GESTÃO DE STAKEHOLDERS EM GESTÃO DE PROJETOS
}

\section{RESUMO}

Em decorrência das atuais mudanças na atualidade evidencia-se um gigantesco aumento dos recursos para o método de projeto e do número e diversidade de novos projetos e conceitos. Dessa forma, o gerenciamento de projetos vem ganhando destaque dentro dos modelos de administração e tem-se transformado num fator para prover velocidade, robustez, consistência e excelência operacional na consecução de projetos. Nota-se também que a gestão de stakeholders em gerenciamento de projetos vem obtendo notoriedade e cada vez mais são feitos esforços para desenvolver competências organizacionais nesta área. Neste contexto, a presente pesquisa teve como objetivo analisar como algumas das maiores indústrias fornecedoras de ferragens do Brasil estão gerenciando os seus stakeholders na gestão de seus projetos. Tendo em vista os procedimentos metodológicos, a pesquisa classifica-se como quali-quantitativa e descritiva. Em vista das características de um levantamento qualitativo, utilizou-se este método na busca de dados acerca da empresa objeto deste estudo, que por sua vez auxiliaram na construção do arcabouço de informações que são requisitos ao desenvolvimento da análise dos dados posteriormente coletados quantitativamente através da aplicação de um formulário estruturado aplicado em forma de entrevista a uma amostra de cinco empresas fornecedoras da área de indústria de ferragens do Brasil. Os resultados mostraram que a maioria das empresas das abordadas não possui uma área formal de gestão projetos, e geralmente utilizam metodologias próprias para gerir seus projetos. Já, quanto à gestão de stakeholders dentro de um projeto é abordada de maneira informal, sem grandes preocupações com o relacionamento com seus stakeholders-chaves.

Palavras-chave: Gestão de Projetos; Stakeholders; Estratégia.

\section{MANAGEMENT OF STAKEHOLDERS IN PROJECT MANAGEMENT}

\begin{abstract}
As a result of current changes is evident today is a large increase of resources for the project method and of the number and diversity of new projects and concepts. The projects management has gotten highlight into the administration models and has been the factor to provide speed, robustness, consistency and operational excellence in the achievement of projects. Also, management of stakeholders in projects management comes getting notoriety and at the same each time efforts to develop organizational skills in the projects management are being doing. In this context, the present research had as objective to examine how some of the largest hardware supplier industries in Brazil are managing their stakeholders in the management of their projects. Describing the methodological procedures, the research is classified as quali-quantitative and descriptive. This method was used to search information about the company object of this study that had assisted the analysis of the quantitative information, obtained through the application of a structured form applied in order to interview a sample of five companies that supply the area of hardware industry in Brazil. Results showed that most of the companies covered lacks a formal area management projects, and generally use their own methodologies to manage their projects. Now, as the management of stakeholders within a project is discussed in an informal manner, with no major concerns about the relationship with its key stakeholders.
\end{abstract}

Keywords: Project Management; Stakeholders; Strategy. 


\section{INTRODUÇÃO}

O gerenciamento de projetos vem sendo utilizado como uma ferramenta muito importante para as organizações suportarem o crescimento e assegurar a sobrevivência em um ambiente excessivamente conturbado, em virtude da sua extrema utilidade para otimizar a alocação dos recursos e o emprego dos esforços. Os benefícios resultantes da utilização dos processos de planejamento, execução e controle de eventos temporários e únicos demonstram se são viáveis as práticas do gerenciamento de projetos.

De acordo com Noro (2006), a mudança não é mais vista como algo ruim, pois hoje em dia ela se remete ao aperfeiçoamento contínuo. Conflitos não são mais vistos como prejuízo para a organização, pois, se resolvidos de forma correta, podem gerar benefícios para a empresa. A gestão de projetos também não é mais vista apenas como um sistema de interesse do plano interno das organizações e sim passou a ser tratada como uma arma competitiva, que representa níveis crescentes de qualidade e ainda agrega valor aos interesses dos clientes.

Qualquer projeto possui um conjunto de entidades ou pessoas com interesses em seus resultados ou que serão influenciados pelos estes, que se conhecem como partes interessadas ou, como representa o termo em inglês, stakeholders (KRETAN et al, 2008). Dependendo dos interesses, os stakeholders podem assumir uma posição estratégica e engajada com relação ao projeto, ou, observando-se por outro lado, podem ser contrários a sua realização e, em casos extremos, até buscar a sua interrupção, contribuindo para seu fracasso.

De acordo com Bourne (2006), o sucesso ou fracasso de um projeto está relacionado com a percepção dos stakeholders sobre o valor criado pelo projeto e a natureza do relacionamento com a equipe do projeto. Se no passado o foco estava direcionado a dimensões como desenvolvimento e controle de escopo, cronograma e orçamento, atualmente o que se vê é a necessidade de balancear o controle e o fortalecimento dos relacionamentos dentro dos projetos, garantido, assim, o engajamento dos stakeholders-chave, aumentando as chances de sucesso.

Esta pesquisa parte da temática relacionada à gestão de stakeholders na gestão de projetos, visando frisar a real importância do gerenciamento das partes interessadas na gestão de projetos, podendo configurar-se como um diferencial competitivo. Tendo em vista o tema relacionado à gestão de stakeholders em gestão de projetos, a presente pesquisa tem como problemática responder à seguinte questão: Como algumas das grandes empresas fornecedoras de ferragens do Brasil, estão gerenciando os seus stakeholders na gestão de seus projetos?

Revista de Gestão e Projetos - GeP, São Paulo, v. 3, n. 1, p 127-158, jan./abr. 2012. 
Tendo em vista o tema apresentado, o objetivo geral deste estudo será o de analisar como algumas das indústrias fornecedoras de ferragens do Brasil, estão gerenciando os seus stakeholders na gestão de seus projetos. Com o intuito de atingir o objetivo geral e a sua complementação de acordo com as etapas consecutivas, os objetivos específicos deste estudo são: Mapear as informações pertinentes a área de gestão de projetos nas empresas participantes; Identificar o grau de influência e categorização dos stakeholders-chave das organizações pesquisadas; Levantar como as empresas identificam seus stakeholders-chave; Conhecer as estratégias utilizadas pelas empresas na gestão de seus stakeholders;

Em uma pesquisa conduzida pelo Dr. William Ibbs, em 52 empresas de várias áreas e tamanhos dos Estados Unidos (IBBS 2002), alguns resultados obtidos atentam para a necessidade de se investir na assimilação da cultura do gerenciamento de projetos: dos pesquisados, apenas $16 \%$ dos projetos saem no tempo e custo previstos; $94 \%$ dos projetos terão ao menos um reinício; o estouro de orçamento chega a $188 \%$ do valor original; somente $61 \%$ dos projetos conseguem manter o escopo original.

Outro estudo realizado por Kelling (2002), em uma amostra de 100 empresas, os resultados seriam de $37 \%$ dos projetos tiveram fracasso, ou foram abandonados, $34 \%$ os projetos foram concluídos, mas com objetivos modificados, qualidade reduzida ou tempo adicional e/ou custo excessivo e por fim, apenas $29 \%$ dos projetos foram concluídos satisfatoriamente. É, portanto, explicita a necessidade de aprofundamentos científicos acerca da temática de gestão de projetos, que contribuam à busca pela redução dos altos índices de insucessos apresentados.

No que tange a gestão de stakeholders, na concepção de Brito e Terra (2009) ainda existem lacunas no gerenciamento dos stakeholders, pois ainda é uma fonte pouco explorada e valorizada, sendo que raramente compõe os sistemas de gestão empresarial. Quando se caracteriza como fonte de valor permite a existência de processos, governança e métricas gerenciadas de forma sistemática (como os processos de gestão de qualidade total). Neste plano ideal, o relacionamento com os stakeholders passa a ser um patrimônio organizacional de alto valor.

\section{GESTÃO DE PROJETOS}

Segundo Sbragia et al. (2009), é importante entender a evolução do gerenciamento de projetos, desde os primórdios até os dias atuais. De acordo com Valeriano (2001) apud Sbragia et

Revista de Gestão e Projetos - GeP, São Paulo, v. 3, n. 1, p 127-158, jan./abr. 2012. 
al. (2009), essa evolução possui três fases distintas: a do conhecimento empírico, a do gerenciamento clássico ou tradicional e, finalmente, a do moderno gerenciamento de projetos.

Para Kerzner (2006), historicamente se admite a gestão de projetos apenas nos setores do mercado orientados a projetos. Neles, o gerente de projetos tinha plena responsabilidade pelos lucros e perdas e foi essa mesma responsabilidade que praticamente forçou as empresas a passarem a tratar a gestão de projetos como uma profissão.

Já nos setores do mercado não orientados a projeto, a sobrevivência de projetos sempre dependerá de produtos ou serviços, jamais de um fluxo continuado de projeto. Na verdade, a maioria das empresas que acreditavam não ser orientadas a projetos era híbrida, ou seja, em geral empresas não orientadas a projetos, mas com uma ou duas divisões voltadas para tal (KERZNER, 2006). Historicamente, as empresas híbridas têm funcionado como se não fossem orientadas a projetos; porém, atualmente, trabalham como empresas orientadas a projetos, conforme a figura 01 :

Figura 01 - Classificação das indústrias pela utilização da gestão de projetos.

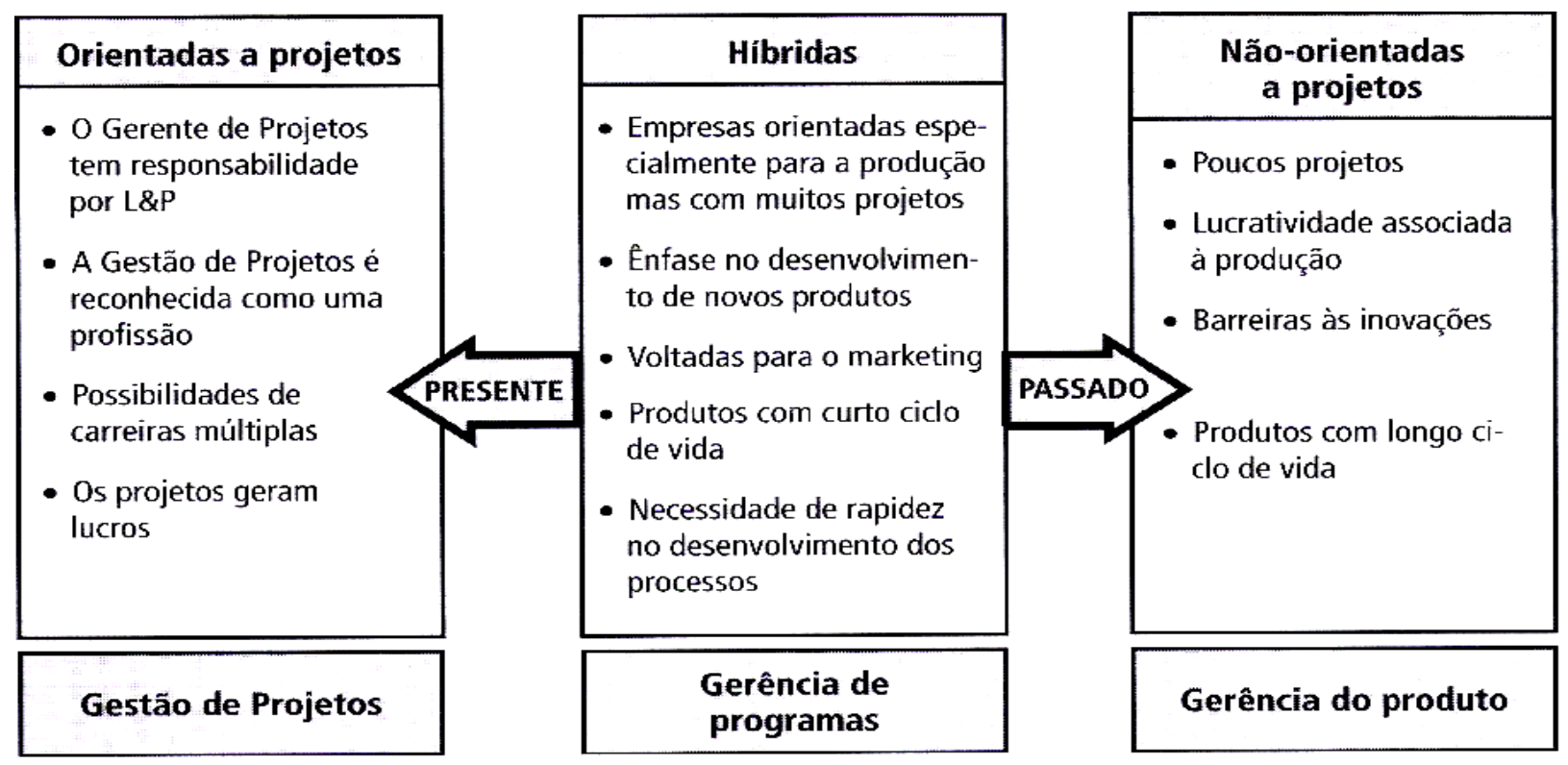

Fonte: KERZNER (2006, p. 19).

Outro fator que contribuiu para a aceitação da gestão de projetos, ainda para Kerzner (2006), foi à economia, especialmente as recessões de 1979/83 e 1989/93. No final da recessão de 1979/83, as empresas reconheciam os benefícios da utilização da gestão de projetos, porém hesitavam quanto a sua implementação, e, por isso, retornaram ao gerenciamento tradicional. A recessão de 1989/93 finalmente aponta o crescimento da gestão de projetos no setor não orientado a projetos. Tratou-se 
de uma recessão caracterizada pelas demissões de gerentes e pessoal administrativo, sendo um período igualmente marcado pelos surgimentos dos partidários da gestão de projetos e do planejamento de objetivos a longo prazo. O autor ressalta na figura 02 , os novos processos que surgiram, contribuindo para a evolução da gestão de projetos:

Figura 2 - Novos processos que surgiram, contribuindo para a evolução da gestão de projetos.

\begin{tabular}{|c|c|c|c|c|c|c|c|c|c|c|c|c|c|c|}
\hline $\begin{array}{l}1960- \\
1985\end{array}$ & 1985 & 1990 & $\begin{array}{l}\text { 1991- } \\
1992\end{array}$ & 1993 & 1994 & 1995 & 1996 & $\begin{array}{l}1997- \\
1998\end{array}$ & 1999 & 2000 & 2001 & 2002 & 2003 & 2004 \\
\hline $\begin{array}{c}\text { Sem } \\
\text { aliados }\end{array}$ & $\begin{array}{c}\text { Gerencia- } \\
\text { mento da } \\
\text { qualidade } \\
\text { total }\end{array}$ & $\begin{array}{l}\text { Engenharia } \\
\text { simultânea }\end{array}$ & $\begin{array}{c}\text { Equipes au- } \\
\text { todir gidas } \\
\text { e delegaçāo } \\
\text { de autori- } \\
\text { dade }\end{array}$ & Reengenharia & $\begin{array}{l}\text { Controle } \\
\text { de custos } \\
\text { do ciclo } \\
\text { de vida }\end{array}$ & $\begin{array}{c}\text { Controle } \\
\text { das mu- } \\
\text { danças do } \\
\text { escopo }\end{array}$ & $\begin{array}{c}\text { Gerencia- } \\
\text { mento } \\
\text { de risco }\end{array}$ & $\begin{array}{l}\text { Escritó- } \\
\text { rios de } \\
\text { projetos } \\
\text { e COEs }\end{array}$ & $\begin{array}{c}\text { Equipes } \\
\text { itine- } \\
\text { rantes }\end{array}$ & $\begin{array}{l}\text { Equipes } \\
\text { Globais }\end{array}$ & $\begin{array}{c}\text { Modelos } \\
\text { de ma- } \\
\text { turidade }\end{array}$ & $\begin{array}{c}\text { Planejamento } \\
\text { estratégico } \\
\text { para Gestāo } \\
\text { de Projetos }\end{array}$ & $\begin{array}{l}\text { Relató- } \\
\text { rios de } \\
\text { Status } \\
\text { Intranet }\end{array}$ & $\begin{array}{l}\text { Modelos } \\
\text { de Plane- } \\
\text { jamento } \\
\text { de capa- } \\
\text { cidade }\end{array}$ \\
\hline
\end{tabular}

Fonte: KERZNER (2006, p. 20).

Segundo Carvalho e Rabechini Jr. (2006), um projeto é uma organização de pessoas dedicadas que visam atingir um propósito e um objetivo específico. Projetos geralmente envolvem gastos, ações ou empreendimentos únicos de altos riscos e devem ser completados numa certa data por um montante de dinheiro, dentro de alguma expectativa de desempenho. No mínimo, todos os projetos necessitam ter seus objetivos bem definidos e recursos suficientes para poderem desenvolver as tarefas requeridas.

Na visão de Woiler e Mathias (2008, p. 14), “um projeto pode ser entendido como um conjunto de informações coletadas e processadas, de modo que simulem uma dada alternativa de investimento para testar sua viabilidade.” Dessa forma, o projeto é o conjunto de informações internas e/ou externas à empresa, coletadas e processadas com o objetivo de analisar uma decisão de investimento. Nessas condições, o projeto não se confunde com as informações, pois ele é entendido como sendo um modelo que incorpora informações qualitativas e quantitativas, procurando simular a decisão de investir em suas aplicações.

Na concepção de Kerzner (2006) um projeto trata de um empreendimento com objetivo bem definido, que consome recursos e opera sob pressões de prazos, custos e qualidade, sendo, em geral, atividades exclusivas em uma empresa. Assim, a gestão de projetos pode ser definida como o planejamento, a programação e o controle de uma série de tarefas integradas, de forma a atingir seus

Revista de Gestão e Projetos - GeP, São Paulo, v. 3, n. 1, p 127-158, jan./abr. 2012. 
objetivos com êxito. Uma gestão de projetos bem sucedida exige planejamento e coordenação extensivos. Dessa maneira, o fluxo de trabalho e a coordenação do projeto devem ser administradas horizontalmente, e não mais verticalmente, como ocorria na gerência tradicional.

Segundo PMBoK Guide (2008), os projetos são normalmente autorizados como resultado de uma ou mais considerações estratégicas. Estas podem ser uma demanda de mercado, necessidade organizacional, solicitação de um cliente, avanço tecnológico ou requisito legal. Neste sentido, as principais características dos projetos são que eles são (1) temporários, possuindo um início e um fim definidos, (2) planejados, executado e controlado, (3) entregam produtos, serviços ou resultados exclusivos, (4) desenvolvidos em etapas e continuam por incremento com uma elaboração progressiva, (5) realizados por pessoas e (6) com recursos limitados.

Para Carvalho e Rabechini (2006, p. 15), “o gerenciamento de projetos inclui planejamento, organização, supervisão e controle de todos os aspectos do projeto, em um processo contínuo, para alcançar seus objetivos." Por outro lado, enfatizam-se a aplicação de conhecimento, habilidades, ferramentas e técnicas como aspectos importantes para a gestão de projetos, objetivando atender ou superar as necessidades e expectativas dos interessados (stakeholders).

Segundo Verzuh (2000), o ciclo de vida de um projeto mostra a sua progressão linear, sendo esta divida em quatro etapas: definir, planejar, executar, concluir. A fase "definir" se inicia quando um projeto e um gerente de projeto são designados na minuta de projeto. A aprovação desse documento significa que todas as partes concordam quanto às metas do projeto, enfoque e equilíbrio entre custos, cronogramas e qualidade.

Com a definição vem a fase do "planejamento", em que é feito o detalhamento do projeto. Depois de aprovado o planejamento, começa a fase de "execução", a qual abrange cerca de noventa por cento das tarefas do projeto; essa fase se completa quando a meta do projeto é atingida. Feito isso, chega-se à fase mais curta do projeto, a "conclusão", a qual abrange três funções: o desenvolvimento do produto, estabelecimento formal do projeto para o cliente e a revisão dos sucessos e falhas dos projetos para melhorias no futuro (VERZUH, 2000).

Já para Carvalho e Rabechini Jr. (2006), os conceitos de gerenciamento de projetos foram abordados através de grupos de processos e de áreas de conhecimento. Mas esses projetos podem ser vistos como fases de ciclo de vida, conceito que tem contribuído para a administração linear dos projetos. Através das fases é possível entender as saídas esperadas, conforme demonstra a figura 03.

Para Kerzner (2006), criar uma metodologia não é tarefa simples, e o fato de seguir uma metodologia em gestão de projetos não é garantia de sucesso e excelência. As metodologias de 
gestão de projetos de classe mundial são integradas a outros processos administrativos, tais como a gestão de mudanças, gerenciamento de riscos, administração de qualidade total e engenharia simultânea. Essas metodologias devem ser fáceis de usar, abrangendo a maioria das situações que podem surgir em um projeto.

Figura 03 - Etapas do ciclo de vida de um projeto.

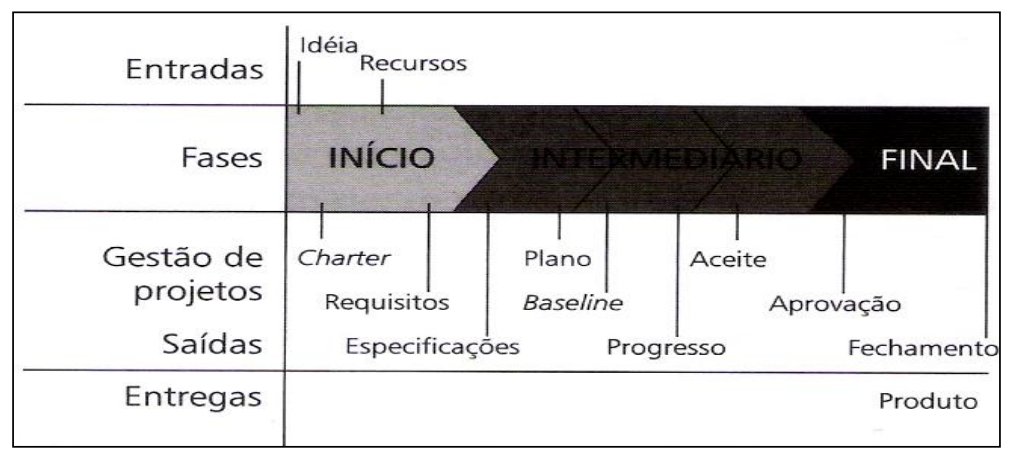

Fonte: CARVALHO e RABECHINI ( 2006, p. 104).

De acordo com o PMBoK Guide (2008), são nove áreas que contribuem para o gerenciamento dos projetos, sendo elas gerenciamento da integração do projeto; gerenciamento do escopo do projeto; gerenciamento do tempo do projeto; gerenciamento dos custos do projeto; gerenciamento da qualidade do projeto; gerenciamento dos recursos humanos do projeto; gerenciamento da comunicação do projeto; gerenciamento dos riscos do projeto; gerenciamento de aquisições do projeto.

A teoria da tripla restrição considera que o projeto possui, como principais restrições, o custo, o tempo e o escopo/qualidade. A escolha entre o escopo e a qualidade depende do foco do projeto. Se, por exemplo, forem consideradas como principais restrições o tempo, o custo e o escopo, a consequência será a qualidade do projeto. Por sua vez, se for considerada a qualidade no lugar do escopo, este será a consequência.

A alteração em algum dos fatores faz com que pelo menos um dos outros se altere. Sendo assim, em um projeto em que as restrições são custo, tempo e escopo, a alteração no escopo do projeto faz com que o tempo e/ou o custo aumente ou diminua (PMI - Project Management Institute, 2004). Dessa maneira, com base na tripla restrição, um projeto termina com sucesso quando o produto ou serviço especificado é entregue contendo tudo o que foi definido no escopo, no prazo, dentro do orçamento previsto e com qualidade. 
De acordo com Kerzner (2006), ao longo dos anos a definição de sucesso vem sofrendo alterações. Nos primórdios da gestão de projetos, o sucesso era medido apenas por termos técnicos, depois passou a ser compreendido de forma que, se o projeto estivesse dentro do prazo, centro do custo preestabelecido e com nível de qualidade desejada, era um projeto de sucesso. $\mathrm{O}$ autor ainda salienta que, atualmente, a melhor explicação do sucesso é aquela que mensura em termos de fatores primários e secundários, sendo aqueles "no prazo", "dentro do orçamento" e "no nível desejado de qualidade". Já estes são "aceitação pelo cliente" e "a concordância do cliente em relação à utilização de seu nome como referência".

Verzuh (2000) expõe que o sucesso na gestão de projetos é dividido em três parâmetros: dentro do prazo, com o produto sendo entregue de acordo com o cronograma; dentro do orçamento, com o projeto cumprindo com a estimativa de custo projetado; alta qualidade, com o produto saindo em alta qualidade - qualidade refere-se ao resultado de um projeto. Esse resultado tem dois componentes: funcionalidade e desempenho.

Segundo Kerzner (2006), é importante compreender que todas as empresas atravessam seus próprios processos de maturidade, e esses devem proceder à excelência. A curva do processo de aprendizado para a maturidade é medida em anos. Em gestão de projetos, a maturidade é o desenvolvimento de sistemas e processos que são por natureza repetitivos e garantem uma alta probabilidade de que cada um deles seja um sucesso.

Na visão de Carvalho e Rabechini Jr. (2006), a concepção e a avaliação de vários estudiosos de que a maturidade em gerência do processo de desenvolvimento de competências tem um caráter gradativo e deriva o conceito de maturidade em gestão de projetos. Os autores identificam as características que diferenciam as organizações imaturas das maduras, conforme o quadro 01.

\begin{tabular}{|c|c|}
\hline ORGANIZAÇÕES IMATURAS & ORGANIZAÇÕES MADURAS \\
\hline $\begin{array}{l}\text { - Ad hoc - processo improvisado por profissionais } \\
\text { e gerentes. } \\
\text { - Não é rigorosamente seguido e o cumprimento } \\
\text { não é controlado. } \\
\text { - Baixa visão do processo e da qualidade. } \\
\text { - A funcionalidade e a qualidade do produto } \\
\text { podem ficar comprometidas para que prazos } \\
\text { sejam cumpridos. }\end{array}$ & $\begin{array}{l}\text { - Coerente com as linhas de ação, o trabalho é } \\
\text { efetivamente concluído. } \\
\text { - Definido, documentado e melhorado } \\
\text { continuamente. } \\
\text { - Com o apoio visível da alta administração e } \\
\text { outras gerências. } \\
\text { - Bem controlado - fidelidade ao processo é } \\
\text { objetivo de auditoria e de controle. } \\
\text { - São utilizadas mediações do produto e do } \\
\text { processo. } \\
\text { - Uso disciplinado da tecnologia. }\end{array}$ \\
\hline
\end{tabular}

Revista de Gestão e Projetos - GeP, São Paulo, v. 3, n. 1, p 127-158, jan./abr. 2012. 
- Arriscado do ponto de vista do uso de nova tecnologia.

- Custos de manutenção excessivos.

- Qualidade difícil de se prever.

Quadro 01 - Construindo competências para gerenciar projetos.

Fonte: CARVALHO e RABECHINI (2006, p. 49).

Para Kerzner (2006), a definição de excelência pode ser desmembrada em duas partes. Em primeiro lugar, a excelência em projetos requer um fluxo contínuo de projetos administrados com sucesso. A segunda definição impõe que as decisões em cada um dos projetos levem em conta os interesses do projeto e da empresa como um todo. As empresas que alcançaram a excelência em gestão de projetos também percebem que ela é um processo contínuo. A melhoria eficaz e contínua na gestão de projetos pode levar a uma consistência que, por sua vez, pode conduzir à excelência.

\subsection{GESTÃO DE STAKEHOLDERS EM GESTÃO DE PROJETOS}

Para Muto (2006), os stakeholders são as pessoas ou organizações ativamente envolvidas nos projetos, de maneira positiva ou negativa ou cujos interesses possam ser afetados com o andamento do projeto ou com o término deste. Dentro do projeto existirão várias escalas de autoridade e responsabilidade para os stakeholders, possibilitando variações durante o seu ciclo de vida.

De acordo com Orth (2009), os stakeholders são pessoas, grupos de pessoas ou entidades que participam ou influenciam o projeto, de maneira direta ou indireta, com interesses em sua evolução ou quando são atingidas por seus resultados. De certa forma, eles têm interesse tanto no sucesso do projeto quanto no contexto em que este se insere.

Para Brito e Terra (2000), stakeholders são pessoas ou organizações interessadas ou afetadas de alguma maneira, não necessariamente econômica. Seu relacionamento com a empresa ou organização é, muitas vezes, indireto e não envolve obrigatoriamente transações comerciais. Esses stakeholders podem estar atrás de uma vantagem, de uma reparação ou uma inserção em um âmbito maior.

A teoria dos stakeholders, segundo Silveira, Yashinaga e Borba (2005), possui seus vínculos principalmente na sociologia, no comportamento organizacional e na política de interesses de

Revista de Gestão e Projetos - GeP, São Paulo, v. 3, n. 1, p 127-158, jan./abr. 2012. 
grupos específicos. Essa teoria pode ser defina por Freeman e McVea (2000) apud Silveira, Yashinaga e Borba (2005, p. 02) como a "formulação e a implementação, pelos administradores, de processos que satisfaçam os grupos interessados na empresa”. A principal função nesse processo seria a de gerenciar e integrar os relacionamentos e os interesses dos acionistas, funcionários, clientes, fornecedores, comunidades, entre outros grupos, de forma a assegurar o sucesso da empresa a longo prazo. Em síntese, é uma abordagem administrativa que enfatiza o gerenciamento ativo do ambiente do negócio, dos relacionamentos entre os participantes e a consequente promoção dos interesses.

De acordo com Brito e Terra (2000), normalmente os stakeholders são distribuídos em um grupo mais direto (como empregados e acionistas, instituições financeiras, fornecedores e clientes) e outro um pouco mais indireto (como comunidades, governo, mídia, grupos de interesse, concorrência e grupos de defesa de interesses).

Segundo o PMI (2004), como consta do PMBoK Guide, os principais stakeholders de um projeto estão apresentados no quadro 02. Conforme Hekdman (2005), o patrocinador do projeto tem autoridade para delegar recursos e impor decisões relacionadas ao projeto, sendo este um stakeholder-chave, assim como o cliente, contratados, fornecedores, gerente do projeto e os gerentes de outros departamentos da organização.

\begin{tabular}{|c|c|}
\hline PRINCIPAIS STAKEHOLDERS & DESCRIÇÃO \\
\hline Gerente de projetos: & Indivíduo responsável pelo gerenciamento do projeto; \\
\hline Cliente/usuário: & $\begin{array}{l}\text { Pessoa ou organização que utilizará o produto do projeto, podendo } \\
\text { existir vários níveis de clientes/usuários; }\end{array}$ \\
\hline Organização executora: & $\begin{array}{l}\text { Empresa cujos funcionários estão diretamente envolvidos na } \\
\text { execução do trabalho do projeto; }\end{array}$ \\
\hline Membros da equipe do projeto: & Grupo que está executando o trabalho do projeto \\
\hline Equipe de gerenciamento de projetos & $\begin{array}{l}\text { Pessoas da equipe do projeto que estão diretamente envolvidas nas } \\
\text { atividades na gestão de projetos; }\end{array}$ \\
\hline Patrocinador: & $\begin{array}{l}\text { Pessoas ou grupo que contribuem com recursos financeiros, em } \\
\text { dinheiro ou espécie, para o projeto; }\end{array}$ \\
\hline
\end{tabular}

Revista de Gestão e Projetos - GeP, São Paulo, v. 3, n. 1, p 127-158, jan./abr. 2012. 


\begin{tabular}{|c|l|}
\hline Influenciadores: & $\begin{array}{l}\text { Pessoas ou grupo que não estão diretamente envolvidos na aquisição } \\
\text { ou uso do produto do projeto, mas que podem influenciar de forma } \\
\text { positiva ou negativa no decorrer do projeto; }\end{array}$ \\
\hline PMO (Project Management Office) & $\begin{array}{l}\text { Se existir na organização executora, este poderá ser uma parte } \\
\text { interessada, se tiver responsabilidade direta ou indireta pelo resultado } \\
\text { do projeto. }\end{array}$ \\
\hline
\end{tabular}

Quadro 02 - Principais stakeholders de um projeto.

Fonte: PMI. (2004, p.67).

Mitchell, Agle \& Wood (1997) apud Teixeira e Domênico (2008) separam os fatores que determinam a importância dos stakeholders em três partes: (1) Poder, definido como a força (coercitiva, utilitária ou regulatória) que pode impor sobre a outra parte em um relacionamento; um ator pode fazer algo que em circunstâncias normais não conseguiria ser feito; (2) Urgência, definido como quando um relacionamento possui uma natureza sensível ao tempo ou quando este relacionamento ou pedido é importante ou crítico para um stakeholder; exige atenção imediata; (3) Legitimidade, definido como uma percepção ou assunção geralmente aceita que as ações de uma entidade são desejáveis ou apropriadas dentro de um sistema de normas, leis, crenças e definições.

Para Daychoum (2005) o gerenciamento ativo das partes interessadas aumenta a probabilidade de o projeto não se desviar do rumo por causa de problemas não resolvidos com os stakeholders. Assim, aumenta a capacidade dos indivíduos operarem em consonância e limita as interrupções durante o projeto. Geralmente, o gerente de projetos é responsável pelo gerenciamento dos stakeholders.

Segundo PMI (2004), o gerenciamento de stakeholders consta como um dos processos da área de gerenciamento de comunicações e pode ser definido como o gerenciamento das comunicações, de modo que atenda às necessidades e resolva os problemas com os stakeholders do projeto, sendo que os grupos de stakeholders envolvidos em um projeto podem ser identificados no quadro 03.

\begin{tabular}{|c|c|}
\hline GRUPO & PARTICIPANTES \\
\hline Stakeholders organizacionais & $\begin{array}{l}\text { Executivos } \\
\text { Gerentes } \\
\text { Empregados } \\
\text { Associações }\end{array}$ \\
\hline
\end{tabular}

Revista de Gestão e Projetos - GeP, São Paulo, v. 3, n. 1, p 127-158, jan./abr. 2012. 


\begin{tabular}{|c|l|}
\hline Stakeholders de produto/mercado & $\begin{array}{l}\text { Clientes } \\
\text { Fornecedores } \\
\text { Comitês Municipais }\end{array}$ \\
\hline Stakeholders do mercado de capitais & $\begin{array}{l}\text { Acionistas } \\
\text { Credores } \\
\text { Bancos }\end{array}$ \\
\hline
\end{tabular}

Quadro 03 - Grupos de stakeholders envolvidos em um projeto.

Fonte: KRETAN (2009, p.63).

Na concepção de Widerman (2004) existe a dificuldade de se identificar os stakeholders e na sua visão deve-se primeiro avaliar o ambiente em que se será realizado o projeto, levando em consideração suas peculiaridades situacionais e locais.

Na figura 04 pode-se identificar o diagrama de Venn proposto por Mitchell, Agles e Wood (1997) apud Trentim (2010) que contém s sete tipos de stakeholders segundo sua legitimidade, poder e urgência no projeto.

Posteriormente para categorizar os stakeholders Trentim (2010) sugere a matriz de Savage et al. (1991), organizando a propensão dos stakeholders em colaborar ou ameaçar as estratégias da empresa, sendo: (1) Stakeholders dispostos a apoiar: alto potencial de cooperação; (2) Stakeholders marginais - não são ameaçadores nem cooperadores; (3) Stakeholders indispostos a cooperar - alto potencial de ameaça; (4) Stakeholders ambíguos - alto potencial em ameaçar e em cooperar, influenciados por interesses conflitantes.

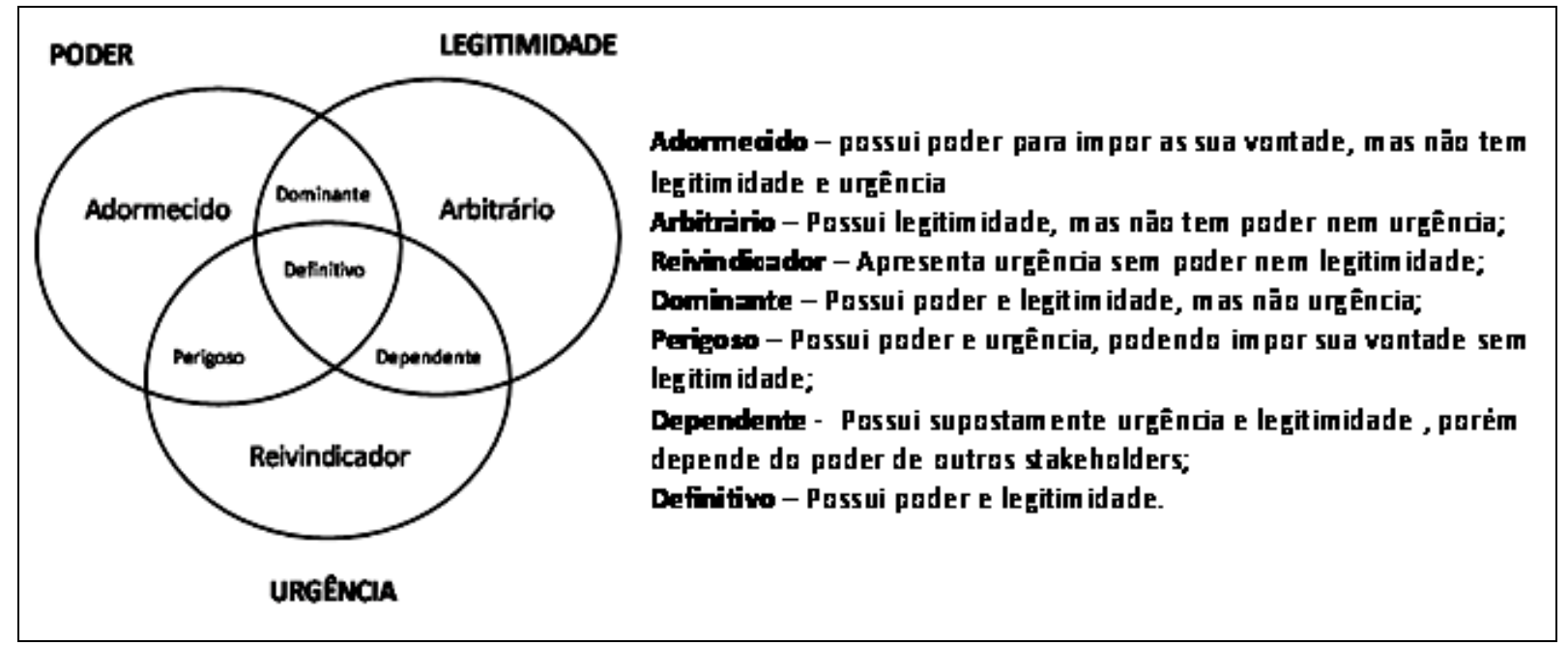

Figura 04 - Tipos de stakeholders de acordo com o seu poder, legitimidade e urgência. Fonte: TRENTIM (2010, p. 30-33).

Revista de Gestão e Projetos - GeP, São Paulo, v. 3, n. 1, p 127-158, jan./abr. 2012. 
Segundo Hanashiro et al. (2008), tendo em vista os diferentes interesses, a administração das empresas passa pela difícil tarefa de conciliar e satisfazer os diferentes interesses dos stakeholders e, com base nisso, os autores definiram as seguintes etapas que constituem uma metodologia de gerenciamento apresentada no quadro 04:

\begin{tabular}{|c|l|}
\hline PASSOS & \multicolumn{1}{|c|}{ DESCRIÇÃO } \\
\hline Primeiro & $\begin{array}{l}\text { É necessário identificar os stakeholders relevantes para a organização, quer sejam externos, } \\
\text { internos, ou que façam interface; }\end{array}$ \\
\hline Segundo & Identificar o subconjunto de stakeholder-chave, isto é, que podem ameaçar a organização; \\
\hline Terceiro & $\begin{array}{l}\text { Diagnosticar os stakeholders-chave que apóiam a empresa, os que não apóiam os que } \\
\text { apresentam aspectos positivos e negativos e os que se posicionam de forma marginal; }\end{array}$ \\
\hline Quarto & $\begin{array}{l}\text { Formular estratégias genéricas que envolvam os stakeholders apoiadores, que defendem a } \\
\text { empresa contra os não-apoiadores, de colaboração com os que apresentam pontos fortes e fracos } \\
\text { no relacionamento com a empresa e de monitoramento dos que se posicionam a margem }\end{array}$ \\
\hline Quinto & $\begin{array}{l}\text { Implementar estratégias genéricas e desenvolver táticas específicas, assumindo a } \\
\text { responsabilidade pelo gerenciamento dos stakeholders-chave. }\end{array}$ \\
\hline
\end{tabular}

Quadro 04 - Medida para gestão baseada em stakeholders.

Fonte: Adaptado de: TEIXEIRA, DOMÊNICO (2008, pg. 340 e 341).

Conforme Kretan et al. (2008), as principais etapas ou atividades a serem trabalhadas num processo de gerenciamento efetivo de stakeholders são apresentadas no quadro 05.

Para Kretan (2008), o sucesso do projeto está intimamente ligado às garantias de que atenderá às necessidades para as quais foi criado. Isso envolve levantar com detalhes as necessidades explícitas e implícitas dos stakeholders e validá-las com as partes interessadas, comprometendo-se a entregar o que foi definido. Já Siegelaub (2005) apud Kretan (2008) identifica três grandes motivos para que o Gerenciamento de Stakeholders seja uma atividade indispensável no desenvolvimento do projeto:

Revista de Gestão e Projetos - GeP, São Paulo, v. 3, n. 1, p 127-158, jan./abr. 2012. 
1. O envolvimento dos stakeholders é crítico para a definição do escopo do projeto e elaboração de estratégias.

2. Em um último momento, são os stakeholders que farão uso dos entregáveis do projeto, com o objetivo de agregar valor ao negócio.

3. O engajamento dos stakeholders produz a assistência e o entusiasmo necessários ao desenvolvimento do projeto.

\begin{tabular}{|c|c|}
\hline ETAPA & DESCRIÇÃO DAS ATIVIDADES \\
\hline $\begin{array}{c}\text { Identificar Missão e Visão } \\
\text { do Projeto: }\end{array}$ & $\begin{array}{l}\text { Cabe ao gerente do projeto e sua equipe manterem constante divulgação da } \\
\text { missão e da visão do projeto. Essa atitude tem papel muito importante na } \\
\text { continuidade do apoio dos stakeholders (SUTTERFIELD, FRIDAY-STROUD } \\
\text { \& SHIVERS-BLACKWELL, } 2006 \text { apud KRETAN et al, 2008) }\end{array}$ \\
\hline Identificar stakeholders: & $\begin{array}{l}\text { A equipe de gerenciamento do projeto deve identificar os stakeholders, seus } \\
\text { requerimentos, interesses e expectativas e, dentro do possível, gerenciar suas } \\
\text { influências em relação aos requerimentos para aumentar a probabilidade de } \\
\text { sucesso. O processo de identificação das necessidades e expectativas dos } \\
\text { stakeholders deve ser contínuo ao longo do projeto. }\end{array}$ \\
\hline $\begin{array}{c}\text { Categorizar/priorizar os } \\
\text { stakeholders: }\end{array}$ & $\begin{array}{l}\text { Os stakeholders, uma vez identificados, podem ser alocados em grupos e } \\
\text { subgrupos de acordo com critérios definidos, como, por exemplo, influência, } \\
\text { interesses, objetivos, nível hierárquico, problemas, riscos, impactos, grau de } \\
\text { relacionamento etc. }\end{array}$ \\
\hline $\begin{array}{l}\text { Definir estratégias de } \\
\text { engajamento: }\end{array}$ & $\begin{array}{l}\text { Conforme Bourne (2005) apud Kretan et al. (2008), com base nas expectativas } \\
\text { dos stakeholders (aquilo que eles esperam do projeto) é o que o projeto espera } \\
\text { dos stakeholders. As estratégias devem ser elaboradas com foco na comunicação } \\
\text { com cada stakeholder ou grupo de stakeholders. }\end{array}$ \\
\hline $\begin{array}{l}\text { Elaborar plano de } \\
\text { gerenciamento de } \\
\text { stakeholders: }\end{array}$ & $\begin{array}{l}\text { Nessa etapa, assim como na elaboração do Plano do Projeto, serão } \\
\text { documentadas todas as ações e atividades que devem ser conduzidas para } \\
\text { alcançar os objetivos propostos. Todo o material elaborado nas etapas anteriores } \\
\text { deve ser utilizado como entrada para esse processo. }\end{array}$ \\
\hline
\end{tabular}

Quadro 05 - Etapas a serem trabalhadas num processo de gerenciamento de stakeholder. Fonte: KRETAN (2009, p. 62). 
Sotille et al. (2006) apud Kretan (2008) apontam o gerenciamento de stakeholders como a ciência de iniciar, planejar, executar e controlar projetos até seu fechamento ordenado, compreendendo a aplicação de conhecimentos, habilidades, ferramentas e técnicas para atingir, ou até mesmo exceder, às necessidades e expectativas de todas as partes interessadas.

Para Bourne (2006 apud autor, ano), a relação que existe entre o gerente do projeto e os stakeholders e, ainda, aqueles entre os stakeholders, formam o ambiente do projeto ou esfera de influência e suporte, do qual um projeto depende para sua existência e que precisa ser gerenciado. Nesse sentido, a autora aponta como aspecto importante a identificação e a gerência dos "sentidos de influência".

\section{METODOLOGIA}

No que tange aos procedimentos metodológicos, a presente pesquisa classifica-se quanto a sua natureza como qualitativa e quantitativa. Na visão de Demo (2000, p.152), “a pesquisa qualitativa quer fazer jus à complexidade da realidade, curvando-se diante dela, não o contrário, como ocorre com a ditadura do método ou demissão teórica que imagina dados evidentes.” Já a pesquisa quantitativa, de acordo com Malhotra (2005), tem como principal objetivo quantificar os dados e generalizar os resultados das amostras para a população de interesse para recomendar um curso de ação final. Diferentemente da qualitativa, tem grande número de casos representativos como amostra, utiliza coleta de dados estruturada e faz análise de dados através da estatística.

No que se referem aos objetivos, a presente pesquisa classifica-se como exploratória e descritiva, sendo que, para Cervo e Bervian (2002), a pesquisa exploratória realiza descrições precisas e corretas da situação e deseja descobrir as relações existentes entre os seus elementos componentes. Para Churchill e Petter (2000), as pesquisas exploratórias, também denominadas desk research, são usadas para gerar hipóteses ou explicações prováveis e identificar áreas para um estudo mais aprofundado sobre a natureza de um problema. Já a pesquisa do tipo descritiva, também chamada de ad-hoc, procura descrever situações e, para Bacha (1998), possuem objetivos bem definidos e formulados, obedece a procedimentos formais, estruturados e dirimidos para a solução de problemas ou avaliação de alternativas de rumos de ação.

Quanto ao plano de coleta dos dados, para execução do presente estudo, primeiramente fezse uso de pesquisa bibliográfica sobre o tema em estudo, os quais serviram de subsídios para a 
confecção do instrumento de coleta de dados utilizado, com vistas a alcançar os objetivos propostos. Para tanto, um formulário estruturado foi confeccionado dividido em cinco partes: a primeira visando levantar dados sobre o perfil das empresas participantes da pesquisa; a segunda buscando levantar informações sobre a gestão de projetos das empresas; a terceira relacionada ao nível de influência dos stakeholders na gestão dos projetos das organizações, de acordo com a escala (1-Sem influência, 2-Pouca influência, 3- Indiferente, 4- Influencia parcialmente e 5-influencia totalmente), bem como a categorização dos referidos stakeholders com base na escala (1-alto potencial de cooperação, 2-não são ameaçadores e nem cooperadores, 3-alto potencial de ameaça e 4-alto potencial em ameaça e em cooperar, influenciados por interesses conflitantes), com base na matriz de Savage et al. (1991); a quarta com base no grau de concordância, no que tange a como as organizações pesquisadas identificam seus stakeholders-chave e a quinta quanto as estratégias utilizadas pelas empresas na gestão de seus stakeholders de acordo com a média de grau de concordância (1 - discordo totalmente, 2 - discordo, 3 - indiferente, 4 - concordo parcialmente e, 5 - concordo totalmente), com base nas etapas a serem trabalhadas num processo de gerenciamento de stakeholder proposta por Kretan (2009).

O presente instrumento foi primeiramente pré-testado para sua validação, em uma das empresas participantes e, posteriormente, aplicado em forma de entrevista aos gestores responsáveis pelas informações necessárias à pesquisa, de uma amostra das maiores empresas fornecedoras da área de indústria de ferragens do Brasil, sejam elas, Bigfer, Ciser, Belenus, Commersul e Negrão, escolhidas pela sua representatividade no setor. Após a coleta, os dados os mesmos foram tabulados com o auxílio do software SPSS 16.0, interpretados e analisados sob a ótica qualitativa.

\section{ANÁLISE DOS RESULTADOS}

Para melhor análise dos dados da pesquisa no quadro 06 observam-se as principais características das empresas participantes da pesquisa. A primeira empresa faz parte do Grupo Bigfer, que está localizado na cidade de Farroupilha, Rio Grande do Sul, Brasil e está a mais de 20 anos no mercado de acessórios para móveis, oferece não só produtos, mas também soluções. Para tanto, desenvolve constantemente novos produtos e avança em tecnologia de produção, para suprir um mercado cada vez mais exigente.

A Bigfer possui uma linha completa com mais de 6.000 itens fabricados e 8.000 itens revendidos, confecciona kits de acessórios para montagem do móvel, o que facilita o controle de 
estoque, a redução de processos e a garantia de qualidade para o moveleiro. Atua também no mercado de embalagens plásticas flexíveis, fornecendo para mais de 10.000 clientes em todo o Brasil.

\begin{tabular}{|c|c|c|c|}
\hline EMPRESAS & $\begin{array}{c}\text { SETOR DE } \\
\text { ATUAÇÃO }\end{array}$ & $\begin{array}{c}\text { TEMPO DE } \\
\text { MERCADO }\end{array}$ & DESCRIÇÃo \\
\hline BIGFER & Moveleiro & 21 anos & $\begin{array}{c}\text { Fábrica de Acessórios para } \\
\text { móveis. }\end{array}$ \\
\hline CISER & Industria Parafusos & 51 anos & $\begin{array}{c}\text { Fabricação e importação de } \\
\text { fixadores. }\end{array}$ \\
\hline BELENUS & Industria Parafusos & 40 anos & $\begin{array}{c}\text { Fabricação e importação de } \\
\text { parafusos e ferramentas. }\end{array}$ \\
\hline COMMERSUL & Atacado Parafusos & 42 anos & $\begin{array}{c}\text { Atacado e varejo de parafusos e } \\
\text { ferramentas em geral. }\end{array}$ \\
\hline NEGRÃortadora e distribuidora de \\
ferramentas em geral.
\end{tabular}

Quadro 06 - Caracterização das empresas participantes.

Fonte: Desenvolvido pelo autor (2010).

Com a aquisição da unidade Hettich do Brasil, em 2010, além de potencializar a liderança no mercado de acessórios para móveis. Em constante crescimento, conta com cerca de 2.400 colaboradores e uma área construída de $91.000 \mathrm{~m}^{2}$. O Grupo Bigfer é composto por 11 unidades: Bigfer Acessórios para Móveis, Bigfer Madeiras, Bigfer Galvanoplastia, Bigfer Fixadores, Bigfer Paraná, Bigfer Filial 05, Lema Embalagens, Lema Plásticos, Showroom São Paulo, Centro de Distribuição Mirassol e Bigbaby.

A segunda empresa participante da pesquisa é a Ciser, que é a maior fabricante de fixadores da América Latina e possui capacidade produtiva diária acima de 250 toneladas e um portfólio de produtos composto de 15.000 itens agrupados em 461 linhas, tudo isso para atender 18.000 clientes no mercado interno e em mais de vinte países. A empresa opera com 1200 colaboradores em duas unidades fabris, a matriz em Joinville/SC e uma filial em Sarzedo/MG, ocupando uma área construída total de 55 mil metros quadrados. Sua ampla linha de produtos atende entre outros os 
segmentos: varejo, atacado, metal-mecânico, construção civil, estruturas metálicas/torres, eletroferragens, agronegócio, automotivo, bike, linhas branca e marrom, eletrônica, ferroviário e moveleiro.

A terceira empresa é a Belenus que oferece soluções completas para a indústria e construção civil fabricando fixadores e distribuindo ferragens, ferramentas e equipamentos para diversas aplicações. Todos os produtos fabricados pela empresa seguem rigorosos processos de produção, cuja eficiência e desempenho já foram atestados por mais de 20 mil clientes em todo território nacional. Com mais de 900 colaboradores, a Belenus possui um extenso parque fabril e 3 centros de distribuição estrategicamente localizados nos estados de São Paulo, Rio Grande do Sul e Espírito Santo, totalizando em todas as suas instalações $180.000 \mathrm{~m}^{2}$ de terreno com mais de $60.000 \mathrm{~m}^{2}$ de área construída. Com capacidade atual de produção de mais de 100 toneladas de parafusos e porcas ao dia, a empresa irá duplicar sua capacidade produtiva, chegando à marca de 200 toneladas diárias com a ativação de sua mais nova unidade fabril em Vinhedo /SP.

A quarta empresa pesquisada é a Commersul Parafusos, que nasceu da força empreendedora e da dedicação de seus sócios-fundadores. Definindo o perfil do empreendimento com um crescimento consistente, hoje a Commersul Parafusos é referência no segmento de fixadores para as linhas agrícola, industrial e metal-mecânica. Atualmente, atendendo a mais de 10.000 clientes, possui um variado estoque, com mais de 20.000 itens, armazenados numa área física de 3.500 metros. Com uma estrutura eficaz e funcional, a Commersul Parafusos investe em profissionais que atuam em todo o Brasil e em países do Mercosul, realizando visitas regulares e fornecendo a assistência técnica necessária. Assim é a Commersul Parafusos, que busca permanentemente a satisfação de seus clientes e colaboradores, através de uma relação de parceria, seriedade e honestidade.

A última empresa participante desta pesquisa é a empresa NEGRÃO, que iniciou suas atividades em 1968 e hoje a empresa é considerada uma das maiores distribuidoras atacadistas do Brasil no ramo de ferragens, ferramentas, material elétrico e de construção. Os negócios foram ampliados recentemente, com a implantação das linhas de produtos agrícolas, utilidades domésticas em seu catálogo de vendas. Atualmente a empresa comercializa mais de 25 mil itens, entre artigos nacionais e importados, trabalha com indústrias renomadas e com produtos com garantia de qualidade e de procedência.

No quadro 07 identificam-se as informações pertinentes a área de Gestão de Projetos (GP) nas empresas participantes.

Revista de Gestão e Projetos - GeP, São Paulo, v. 3, n. 1, p 127-158, jan./abr. 2012. 


\begin{tabular}{|c|c|c|c|}
\hline EMPRESAS & $\begin{array}{c}\text { POSSUI ÁREA } \\
\text { FORMAL DE GP }\end{array}$ & $\begin{array}{c}\text { POSSUI CERTIFICAÇÃo } \\
\text { EM GP }\end{array}$ & $\begin{array}{c}\text { METODOLOGIA DE } \\
\text { GP }\end{array}$ \\
\hline BIGFER & Sim & Não & Por diretrizes \\
\hline CISER & Não & Não & Própria \\
\hline BELENUS & Não & Não & Própria \\
\hline COMMERSUL & Não & Não & Própria \\
\hline NEGRÃo & Não & Não & \\
\hline
\end{tabular}

Quadro 07 - Caracterização das empresas participantes.

Fonte: Desenvolvido pelo autor (2010).

O quadro 07 mostra que somente uma das empresas participantes possui uma área formal na Gestão de Projetos (GP), sendo que as demais empresas utilizam de práticas de gerenciamento de projetos, porém, sem área formalizada na empresa. No que se refere a certificação em GP, nenhuma empresa possui certificação na gestão de projetos e $80 \%$ das empresas utiliza uma metodologia própria de gerenciamento de projetos.

Quanto ao nível de capacitação em gestão de projetos dos gerentes de projetos das organizações pesquisadas, apenas duas empresas, apresentaram profissionais com capacitação formal em gerenciamento de projetos, sendo que as demais empresas não apresentam nenhum profissional com capacitação formal para o gerenciamento de projetos, ou seja, possuem responsáveis pelos projetos sem conhecimentos aprofundados na gestão de projetos.

No que se refere ao tempo em que as organizações trabalham com a gestão de projetos, a empresa Bigfer destacou que desde 1993 a empresa trabalha com projetos, entretanto, não possui uma área formal de gestão de projetos. Já a Ciser citou que trabalha com algumas ferramentas formais de gestão de projetos a menos de cinco anos. A empresa Belenus trabalha com algumas práticas de gestão de projetos a menos de um ano e a Ferragem Negrão trabalha de maneira informal a mais de dez anos.

Revista de Gestão e Projetos - GeP, São Paulo, v. 3, n. 1, p 127-158, jan./abr. 2012. 


\subsection{A GESTÃO DE STAKEHOLDERS DAS EMPRESAS PARTICIPANTES}

Na tabela 01 identifica-se o nível de influência dos stakeholders na gestão dos projetos das organizações, de acordo com a escala (1-Sem influência, 2-Pouca influência, 3- Indiferente, 4Influencia parcialmente e 5-influencia totalmente), bem como a categorização dos referidos stakeholders com base na seguinte escala (1-alto potencial de cooperação, 2-não são ameaçadores e nem cooperadores, 3-alto potencial de ameaça e 4-alto potencial em ameaça e em cooperar, influenciados por interesses conflitantes).

De acordo como exposto na tabela 02 , os stakeholders que são considerados mais influentes para as empresas analisadas são os gerentes de projeto com média de 4,80, sendo que isso mostra que o responsável pelo projeto é considerado o principal stakeholder no com andamento dom projeto. Em segundo lugar no grau de influência com média de 4,60, estão os clientes/usuários e a equipe de projetos, os quais são considerados muito importantes para o desenvolvimento do projeto. Em terceiro lugar encontram-se empatados os executivos e os acionistas com média de 4,40, sendo considerados também de grande influência na gestão de projetos pelas empresas analisadas.

Ao verificarem-se os stakeholders de menor influência na gestão de projetos, na visão das empresas participantes da pesquisa, pode-se observar que as associações foram consideradas as menos influentes com média de 2,40. Outro stakeholders considerado pouco influente pelas empresas pesquisadas, com média de 2,80, foram as faculdades. A mídia ficou em terceiro lugar na questão de menor influencia, com média de 3,00. É interessante ressaltar que outros três fatores ficaram com a mesma média que corresponde a pouco grau de influência, sendo eles as seguradoras, entidades empresarias e comunidade do entorno com média 3,20.

Tabela 01- Caracterização e Nível de influência dos stakeholders.

\begin{tabular}{|c|c|c|c|c|c|}
\hline \multirow{2}{*}{$\begin{array}{c}\text { INFLUÊNCIA E CATEGORIZAÇÃO DOS } \\
\text { STAKEHOLDERS }\end{array}$} & & \multicolumn{2}{|c|}{ INFLUÊNCIA } & \multicolumn{2}{|c|}{ CATEGORIZAÇÃO } \\
\hline & $\mathbf{N}$ & MEDIA & DESVIO & MEDIA & DESVIO \\
\hline GERENTES DE PROJETOS & 5 & 4,8000 &, 44721 & 1,0000 & ,00000 \\
\hline EXECUTIVOS & 5 & 4,4000 &, 54772 & 1,4000 & 89443 \\
\hline
\end{tabular}

Revista de Gestão e Projetos - GeP, São Paulo, v. 3, n. 1, p 127-158, jan./abr. 2012. 
A Gestão de Stakeholders em Gestão de Projetos

\begin{tabular}{|c|c|c|c|c|c|}
\hline EQUIPE DE PROJETOS & 5 & 4,6000 &, 54772 & 1,0000 & ,00000 \\
\hline PMO (PROJECT MANAGEMENT OFFICE) & 5 & 4,0000 & ,70711 & 1,5000 &, 57735 \\
\hline COLABORADORES & 5 & 4,2000 & ,83666 & 1,6000 & ,89443 \\
\hline ASSOCIAÇÕES, & 5 & 2,4000 & ,54772 & 2,2000 & ,44721 \\
\hline CLIENTES/USUÁRIO & 5 & 4,6000 & 89443 & 1,4000 & ,89443 \\
\hline FORNECEDORES & 5 & 4,0000 &, 70711 & 1,2000 & ,44721 \\
\hline $\begin{array}{l}\text { GOVERNO/COMITÊS MUNICIPAIS E/OU } \\
\text { ESTADUAIS }\end{array}$ & 5 & 4,0000 &, 00000 & 1,4000 & 54772, \\
\hline ACIONISTAS & 5 & 4,4000 &, 54772 & 1,0000 & 00000 \\
\hline INVESTIDORES & 5 & 4,2000 & ,44721 & 1,4000 &, 89443 \\
\hline CREDORES & 5 & 3,8000 & ,44721 & 1,8000 & ,83666 \\
\hline BANCOS & 5 & 3,4000 &, 54772 & 1,8000 &, 83666 \\
\hline SEGURADORAS & 5 & 3,2000 & ,83666 & 1,8000 & ,83666 \\
\hline ENTIDADES EMPRESARIAIS & 5 & 3,2000 & ,83666 & 1,6000 &, 54772 \\
\hline MÍDIA & 5 & 3,0000 &, 70711 & 1,8000 & ,44721 \\
\hline UNIVERSIDADES & 5 & 2,8000 & 83666 & 1,8000 & ,44721 \\
\hline COMUNIDADE DO ENTORNO & 5 & 3,2000 & ,83666 & 3,0000 & 1,41421 \\
\hline
\end{tabular}

Revista de Gestão e Projetos - GeP, São Paulo, v. 3, n. 1, p 127-158, jan./abr. 2012. 
De acordo com a categorização, observa-se na tabela 02 que, três itens foram considerados como tendo um alto potencial de cooperação para o andamento de um projeto, que foram eles gerente de projetos, equipe de projetos, e os acionistas com média de 1,00. Outros quatro itens ficaram igualitariamente com alto potencial de cooperação no projeto que foram os executivos, os clientes e usuários do projeto, governos, comitês estaduais e municipais e ainda os investidores do projeto, com média de 1,40. Estes fatores citados foram considerados pelas empresas participantes os que mais cooperam para o desenvolvimento de um projeto.

No que tange a questão da categorização do stakeholders, os itens considerado com alto grau de ameaça ou ainda alto potencial em ameaça e em cooperar, influenciados por interesses conflitantes, em primeiro lugar como fator considerado mais ameaçador para o andamento dos projetos encontrase a comunidade do entorno do projeto, com média 3,00, pois, para empresas analisadas a comunidade do entorno do projeto pode se tornar o principal fator de risco para o desenvolvimento do projeto. Uma maneira de amenizar esta ameaça, realizar pesquisa prévia com vistas à consulta a comunidade que será envolvida pelo projeto, acerca dos aspectos inerentes dos projetos, segundo PMI (2004), o gerenciamento de stakeholders consta como um dos processos da área de gerenciamento de comunicações de modo que atenda às necessidades e resolva os problemas com os stakeholders do projeto, ou seja, a comunicação com a comunidade é de suma importância para que não ocorra nenhum problema no gerenciamento do projeto.

Outro stakeholder considerado uma ameaça para o andamento do projeto foram às associações e, isso também pode ser proveniente de uma comunicação ineficiente, pois de acordo com Daychoum (2005) o gerenciamento ativo das partes interessadas aumenta a probabilidade de o projeto não se desviar do rumo por causa de problemas não resolvidos com os stakeholders.

Na tabela 02 verifica-se a média obtida quanto ao grau de concordância, no que tange a como as organizações pesquisadas identificam seus stakeholders-chave de acordo com a média de grau de concordância (1 - discordo totalmente, 2 - discordo, 3 - indiferente, 4 - concordo parcialmente e, 5 - concordo totalmente)

A que questão que mostra se a identificação dos stakeholders-chave relaciona-se ao grau de legitimidade que exercem no projeto e/ou organização ganhou destaque perante as demais questões, com média de 4,00. Segundo as empresas envolvidas na pesquisa, relacionando os stakeholders com o grau de legitimidade que exercem no projeto a probabilidade deste obter o sucesso é superior.

Revista de Gestão e Projetos - GeP, São Paulo, v. 3, n. 1, p 127-158, jan./abr. 2012. 
Tabela 02 - Como as empresas identificam seus stakeholders-chave;

\begin{tabular}{|l|c|c|c|c|c|}
\hline \multicolumn{1}{|c|}{ IDENTIFICAÇÃO DOS STAKEHOLDERS-CHAVE } & N & MÍNIMO & MAXIMO & MEDIA & DESVIO \\
\hline $\begin{array}{l}\text { 1.Em todo projeto é realizada pelo gerente e equipe do projeto } \\
\text { e junto à alta administração, a identificação dos stakeholders- } \\
\text { chave do projeto? }\end{array}$ & 5 & 3,00 & 3,00 & 3,0000 &, 00000 \\
\hline $\begin{array}{l}\text { 2. A empresa possui critérios específicos para a identificação } \\
\text { dos stakeholders chave de cada projeto? }\end{array}$ & 5 & 2,00 & 5,00 & 3,0000 & 1,22474 \\
\hline $\begin{array}{l}\text { 3. A identificação dos stakeholders-chave relaciona-se ao grau } \\
\text { de poder que exercem no projeto e/ou organização, ou seja, os } \\
\text { que podem impor sua vontade na organização? }\end{array}$ & 5 & 3,00 & 4,00 & 3,4000 &, 54772 \\
\hline $\begin{array}{l}\text { 4. A identificação dos stakeholders-chave relaciona-se ao grau } \\
\text { de legitimidade que exercem no projeto e/ou organização? }\end{array}$ & 5 & 3,00 & 5,00 & 4,0000 &, 70711 \\
\hline $\begin{array}{l}\text { 5. A identificação dos stakeholders-chave relaciona-se ao grau } \\
\text { de urgência que exercem no projeto e/ou organização? }\end{array}$ & 5 & 1,00 & 4,00 & 2,2000 & 1,09545 \\
\hline $\begin{array}{l}\text { 6. A empresa avalia os stakeholders de cada projeto, } \\
\text { separando-os em apoiadores/ou cooperadores e os que } \\
\text { ameaçam de alguma forma o projeto e/ou empresa? }\end{array}$ & 5 & 1,00 & 5,00 & 3,4000 & 1,51658 \\
\hline
\end{tabular}

Duas questões que obtiveram a média de 3,40 e a primeira diz respeito a se a identificação dos stakeholders-chave relaciona-se ao grau de poder que exercem no projeto e/ou organização, ou seja, os que podem impor sua vontade na organização e na visão dos pesquisados, isto depende de cada projeto realizado e o projeto de certa forma é influenciado pelos stakeholders de maior poder na organização. A segunda questão relacionou-se a se a empresa avalia os stakeholders de cada projeto, separando-os em apoiadores/ou cooperadores e os que ameaçam de alguma forma o projeto e/ou empresa e, para os pesquisados, a separação dos stakeholders-chave é fundamental importância para deixar a equipe de projetos ciente de quem é favor e quem é contra o desenvolvimento do projeto.

De acordo com a tabela 03 a questão que aponta se em todo projeto é realizada pelo gerente e equipe do projeto e junto à alta administração, a identificação dos stakeholders-chave do projeto, 
obteve unanimidade na resposta com média igual a 3,00, onde todas as empresas participantes da pesquisa foram indiferentes com a questão, o que mostra que não há grande preocupação com a identificação formal dos stakeholders-chave pelo gerente e equipe de projeto junto à alta administração, pois de acordo com as pesquisadas a identificação dos stakeholders-chave junto a alta administração é feita apenas para projetos estratégicos e de clientes, sendo que, projetos menores podem ser definidos apenas pela equipe do projeto.

Também com média 3,00 identifica-se a questão de se a empresa possui critérios específicos para a identificação dos stakeholders-chave de cada projeto e foram percebidas variações nas respostas, onde as empresas responderam que não existem critérios para identificação dos stakeholders, ou que cada projeto tem seus critérios específicos para identificação dos mesmos.

A questão com menor média de concordância está ligada a se a identificação dos stakeholders-chave relaciona-se ao grau de urgência que os mesmos exercem no projeto e/ou organização, com média de 2,20. Na visão dos participantes da pesquisa, todos os projetos devem ter a identificação dos stakeholders-chave e não é a urgência que define esta identificação.

Na tabela 03 verifica-se a média obtida quanto ao grau de concordância, no que tange as estratégias utilizadas pelas empresas na gestão de seus stakeholders.

Tabela 03 - Estratégias na gestão dos stakeholders.

\begin{tabular}{|l|l|l|l|l|l|}
\hline ESTRATÉGIAS DE GESTÃO DOS STAKEHOLDERS & N & MINIMO & MAXIMO & MEDIA & DESVIO \\
\hline $\begin{array}{l}\text { 1. A organização busca formular estratégias genéricas que } \\
\text { envolvam os stakeholders apoiadores, para que estes tornem- } \\
\text { se seus defensores contra os não-apoiadores? }\end{array}$ & 5 & 1,00 & 4,00 & 2,0000 & 1,22474 \\
\hline $\begin{array}{l}\text { 2. A organização busca formular estratégias para gerenciar os } \\
\text { stakeholders que ameaçam o sucesso de seu projetos de forma } \\
\text { a minimizar seus impactos? }\end{array}$ & 5 & 1,00 & 4,00 & 2,6000 & 1,34164 \\
\hline $\begin{array}{l}\text { 3. A empresa busca monitorar os stakeholders que se } \\
\text { posicionam a margem (indiferentes como apoiadores ou não } \\
\text { apoiadores), avaliando os pontos fortes e fracos do seu } \\
\text { relacionamento com a empresa? }\end{array}$ & 5 & 1,00 & 4,00 & 2,0000 & 1,41421 \\
\hline $\begin{array}{l}\text { 4. A organização costuma desenvolver uma comunicação } \\
\text { eficiente e continua com seus stakeholders-chave? }\end{array}$ & 5 & 4,00 & 5,00 & 4,4000 &, 54772 \\
\hline
\end{tabular}

Revista de Gestão e Projetos - GeP, São Paulo, v. 3, n. 1, p 127-158, jan./abr. 2012. 


\begin{tabular}{|l|c|c|c|c|c|}
\hline $\begin{array}{l}\text { 5. A organização preocupa-se em avaliar as reais necessidades } \\
\text { dos stakeholders internos da organização? }\end{array}$ & 5 & 2,00 & 5,00 & 3,2000 & 1,30384 \\
\hline $\begin{array}{l}\text { 6. A organização busca desenvolver uma política de portas } \\
\text { abertas focando no envolvimento continuo dos stakeholders- } \\
\text { chave com a organização? }\end{array}$ & 5 & 2,00 & 5,00 & 3,8000 & 1,09545 \\
\hline $\begin{array}{l}\text { 7. A empresa da o suporte necessário aos stakeholders-chave, } \\
\text { como por exemplos, fornecer o feedback constante sobre o } \\
\text { andamento dos projetos. }\end{array}$ & 5 & 2,00 & 5,00 & 3,6000 & 1,14018 \\
\hline
\end{tabular}

Observa-se, que a questão relacionada a se a organização costuma desenvolver uma comunicação eficiente e continua com seus stakeholders-chave ganha destaque com média de 4,40, ou seja, os pesquisados concordam com a questão. De acordo com os pesquisados, quando os stakeholders são identificados as empresas procuram a busca do feedback constante com os mesmos em cada fase do projeto, assim como, que todos os stakeholders envolvidos tenham informações corretas do andamento do projeto.

Posteriormente com média de 3,80 de grau de concordância, verifica-se que as organizações buscam, desenvolver uma política de portas abertas focando no envolvimento continuo dos stakeholders-chave com a organização, bem como que as empresas dão o suporte necessário aos stakeholders-chave, como por exemplo, fornecer o feedback constante sobre o andamento dos projetos. Em seguida com média 3,60 vem a questão se a empresa da o suporte necessário aos stakeholders-chave, como por exemplos, fornecer o feedback constante sobre o andamento dos projeto pois, de acordo com os entrevistados, o suporte necessário é dado através de reuniões marcadas com os interessados nos resultados, fornecendo assim o feedback do projeto.

De acordo com a tabela 04 as questões mais negativas, estão relacionadas as estratégias utilizadas pelas empresas na gestão de seus stakeholders se a organização preocupa-se em avaliar as reais necessidades dos stakeholders internos da organização, com média de 3,20 de grau de concordância. Verifica-se que as empresas possuem um ponto negativo quanto ao suporte aos stakeholders internos da organização, sendo que este ponto necessita ser trabalhado, pois, estes devem sempre estar a par de cada novo passo do projeto, a organização necessita verificar as necessidades de seus stakeholders internos, pois são eles que proporcionam o desenvolvimento do projeto.

Revista de Gestão e Projetos - GeP, São Paulo, v. 3, n. 1, p 127-158, jan./abr. 2012. 
Com média relativamente baixa de concordância, encontra-s a alternativa que questiona se a organização busca formular estratégias para gerenciar os stakeholders que ameaçam o sucesso de seus projetos de forma a minimizar seus impactos, com média de 2,60. Para os participantes da pesquisa, isto ocorre de maneira informal, mas pouco eficaz, e tentam, na medida do possível, avaliar os stakeholders que ameaçam o projeto ou apenas procuram saber o porquê de estarem contra o desenvolvimento do empreendimento. Destaca-se que o relacionamento com estes stakeholders necessita ser muito bem trabalho, pois estes podem vir até mesmo a influenciar no cancelamento do projeto.

Duas alternativas obtiveram visivelmente um baixo grau de concordância, com média de 2,00. Primeiramente se a organização busca formular estratégias genéricas que envolvam os stakeholders apoiadores, para que estes se tornem seus defensores contra os não-apoiadores. Neste ponto, algumas empresas responderam que não possuem nenhuma estratégia e outras que, raramente utilizam estratégias que envolvam seus apoiadores. Ressalta-se que, este ponto necessita de atenção das empresas participantes, pois além de ter stakeholders que apenas apóiam é possível conseguir uma parceria para formular estratégias contra os não apoiadores do projeto.

Posteriormente verifica-se a questão de se a empresa busca monitorar os stakeholders que se posicionam a margem (indiferentes como apoiadores ou não apoiadores), avaliando os pontos fortes e fracos do seu relacionamento com a empresa. Neste quesito a maioria dos participantes foi indiferente ou discordaram com a questão, sendo que as empresas participantes, em geral, não fazem está avaliação e o monitoramento destes stakeholders seria relevante para tornar os indiferentes apoiadores dos projetos em possíveis apoiadores, garantindo maior credibilidade ao sucesso dos projetos.

Ao questionar acerca de que outras estratégias as organizações utilizam para gerencia seus stakeholders, verificou-se que as empresas entrevistadas na pesquisa, não possuem estratégias formais para gestão de stakeholders, mas sim linhas de conduta com algumas regras e normas, que variam de acordo com as necessidades de cada projeto.

Já quanto aos resultados advindos da gestão de seus stakeholders, de acordo com as empresas pesquisadas, ressaltam que o conhecimento das expectativas e ameaças permite ações de prevenção e identificação dos riscos, também foi citado que os resultados são de uma maior proximidade e melhor comunicação garantindo os prazos e o bom andamento do projeto.

De acordo com a pesquisa, percebe-se que as empresas participantes não possuem áreas formais de gestão de projetos, bem como, uma gestão de stakeholders formal e efetiva, mas utilizam 
de algumas ferramentas para verificar e desenvolver projetos. Fica evidente que a formalização da área de gestão de projetos, além de práticas e ferramentas formais e planejadas agregaria conhecimentos para que as empresas pesquisadas melhorem ainda mais os conhecimentos já utilizados na gestão de seus projetos.

\section{CONCLUSÃO}

A prática do gerenciamento de projetos nas empresas vem, finalmente, adquirindo seu lugar no cenário empresarial e atualmente, percebe-se o uso freqüente dos processos de gerenciamento de projetos no planejamento, na execução e no controle das organizações, sendo que, neste processo, o gerenciamento eficaz dos stakeholders ganha importância. Neste contexto, a presente pesquisa partiu do objetivo de analisar como as indústrias fornecedoras de ferragens da empresa Manhago Parafusos e Ferragens Ltda, da cidade de Santa Maria/RS, estão gerenciando os seus stakeholders na gestão de seus projetos.

Quanto a área de gestão de projetos nas empresas participantes, levantou-se que apenas uma das empresas participantes possui uma área formal na gestão de projetos e as demais empresas utilizam de práticas de gerenciamento de projetos, porém sem uma área formalizada. Já no que se refere à certificação em gestão de projetos, nenhuma empresa possui certificação e $80 \%$ das empresas utiliza uma metodologia própria de gerenciamento de projetos.

No que se refere ao grau de influência e categorização dos stakeholders-chave das organizações pesquisadas percebeu-se que os stakeholders que são considerados mais influentes para as empresas participantes da pesquisa são os gerentes de projeto. Já os stakeholders menos influentes para o gerenciamento de um projeto foram às associações e universidades. Quanto à categorização dos stakeholders nos projetos, os considerados como tendo um alto potencial de cooperação para o andamento de um projeto foram os gerente de projetos, equipe de projetos e os acionistas, sendo considerados os principais cooperadores. Já os stakeholders que possuem alto potencial em ameaçar e em cooperar, influenciados por interesses conflitantes, em primeiro lugar encontra-se a comunidade do entorno do projeto, pois, para as empresas pesquisadas a comunidade pode se tornar o principal fator de risco para o desenvolvimento de um projeto se não gerenciada eficazmente.

Revista de Gestão e Projetos - GeP, São Paulo, v. 3, n. 1, p 127-158, jan./abr. 2012. 
Já quanto a como as empresas identificam seus stakeholders-chave, pode-se ressalta que, os stakeholders-chave são identificados pela empresa de acordo com o grau de legitimidade que exercem no projeto e/ou organização e através do grau de poder que exercem no projeto e/ou organização, ou seja, os que podem impor sua vontade na organização. Verificou-se que as empresas separam stakeholders como apoiadores/ou cooperadores e os que ameaçam de alguma forma cada projeto, sendo estas as principais formas apontadas pelas empresas como formas de identificar seus stakeholders-chave.

Já quanto a formular estratégias genéricas que envolvam os stakeholders apoiadores, para que estes se tornem possíveis defensores da empresa contra os não-apoiadores, bem como se monitoram os stakeholders que se posicionam a margem (indiferentes como apoiadores ou não apoiadores), as empresas não possuem estratégia ou raramente utilizam estratégias que envolvam seus apoiadores e se demonstraram não fazer nenhum tipo de avaliação, para definição posterior de estratégias que poderiam sustentar ainda mais seus projetos.

No que se refere às estratégias utilizadas pelas empresas na gestão de seus stakeholders, verificou-se que as pesquisadas não possuem estratégias formalizadas para esta gestão, mas sim, apenas modos de conduzir através de regras e normas que variam de acordo com as expectativas de cada projeto, pois o conhecimento das expectativas e ameaças permite ações que previnem e identificação os riscos, além de os resultados serem de uma maior proximidade e melhor comunicação garantindo que o cronograma e as expectativas do projeto sejam cumpridos.

Portanto com base na pesquisa efetuada pode-se chegar concluir que nenhuma empresa utiliza estratégias formais de gestão de projetos, mas que existem pessoas responsáveis pelo desenvolvimento de projetos nas empresas. Sabendo do grande potencial de todas as empresas pesquisadas, a formalização da área de gestão de projetos contribuiria para organização dos processos e identificação dos possíveis riscos inerentes a cada projeto, contribuindo para uma sólida evolução no gerenciamento do portfólio de seus projetos e consequentemente das lições aprendidas destes.

Quanto à influência e categorização dos stakeholders, as associações e a comunidade do entorno do projeto merecem profunda atenção das empresas, pois dependendo do projeto, podem até mesmo embargar o seu andamento. Sugere-se que as empresas desenvolvam um plano de comunicação eficiente e eficaz com seus stakeholders-chave, o que pode tornar possível, torná-los até mesmo apoiadores de seus projetos.

Revista de Gestão e Projetos - GeP, São Paulo, v. 3, n. 1, p 127-158, jan./abr. 2012. 
No que se refere à identificação dos stakeholders, as empresas demonstraram deficiência em tornar seus stakeholders defensores de seus projetos e demonstraram indiferença aos stakeholders indiferentes ao projeto. Destaca-se que, estas são duas estratégias que, se forem bem desenvolvidas e utilizadas, podem gerar resultados positivos para as empresas e um bom tema para dar continuidade a esta pesquisa seria, ou seja, analisar a influência no sucesso da gestão de projeto dos stakeholders defensores e indiferentes quanto aos projetos desenvolvidos pelas empresas pesquisadas.

\section{REFERÊNCIAS}

Andrade, Maria Margarida de. Introdução à metodologia do trabalho científico: elaboração de trabalhos na graduação. 9 ed. São Paulo: Atlas, 2009.

Bacha, Maria de Lourdes. Introdução à pesquisa de marketing. São Paulo: CenaUn, 1998.

Brito, Antônio Carlos; Terra, José Claudio C. Posicionamento Estratégico e Sistematização da Gestão dos Stakeholders. Disponível em Biblioteca Terra Forum Consultores, 2009.

Carvalho, Marly Monteiro de. Rabechini Jr., Roque. Construindo competências para gerenciar projetos: teorias e casos. São Paulo: Atlas, 2006.

Cervo, Amado Luiz; Bervian, Pedro Acino. Metodologia científica. São Paulo: Person prentice Hall, 2002.

Churchill Jr., Gilberto A.; Peter, J. Paul. Marketing criando valor para os clientes. 2 ed. São Paulo: Saraiva, 2000.

Daychoum, Merhi. Gerência de projetos: programa delegacia legal. Rio de Janeiro: Brasport, 2005.

Demo, Pedro. Metodologia do conhecimento científico. São Paulo: Atlas, 2000.

Hanashiro, D. M. M. et al. Gestão do Fator Humano: uma visão baseada em stakeholders. São Paulo: Saraiva, 2007.

Heldman, Kim. Gerência de projetos: guia para o exame oficial do PMI. Rio de Janeiro: Elsevier, 2005. 
Kerzner, Harold. Gestão de projetos: as melhores práticas. 2 ed. Porto Alegre: Bookman, 2006.

Kretan , Agostinho. et al. Gerenciamento de stakeholders: um fator critico para o sucesso em projetos Revista Mundo Project Management . São paulo, n.24, v.4, p.62 , dezembro 2009.

Malhotra, Naresh K. et al. Introdução à pesquisa de marketing. São Paulo: Pearson Prentice Hall, 2005.

Muto, Claudio Adonai. Exame PMI: a bíblia. Rio de Janeiro: Brasport, 2006.

Noro, Greice. A maturidade em gerenciamento de projetos logísticos: o caso América Latina Logística. Dissertação de mestrado. Universidade Federal de Santa Maria - Centro de Tecnologia - Programa de Pós-Graduação em Engenharia de Produção, 2006.

Oliveira, Silvio Luiz. Tratado de Metodologia Científica. 2 ed. São Paulo: Pioneira Thomson Learning, 2004.

Orth, Afonso Inácio. Planejamento e gerência de projetos. Porto Alegre: EDIPUCRS, 2009.

PMI. A Guide to the Project Management Body of Knowledge Third Edition (PMBOK Guide). Newtown Square, PA: Project Management Institute, 2004.

PMBOK. Um guia do conjunto de conhecimentos em gerenciamento de projetos. 4 ed. Pensilvânia: Project Management Institute, 2008.

Sbragia, Roberto et al. Gerenciamento de Projetos . Revista Mundo Project Management. São Paulo, n.27, v.5, p.52, junho 2009.

Silva, Edna Lucia. Metodologia de pesquisa e elaboração de dissertação. 3 ed. Florianópolis: Laboratório de Ensino a Distância da UFSC, 2001.

Silveira, Alexadre; Yashinaga, Claudia; Borba, Paulo. critica a teoria dos stakeholders como função-objeto corporativa. Caderno de Pesquisas em Administração, São Paulo, v. 12, n. 1, p. 33-42, janeiro/março 2005.

Trentim, Mário, H. Gerenciamento de stakeholders: o case BP - Golfo do México. Revista Mundo Project, ano 6, n⿳⺈ 34 - ago/set de 2010.

Vergara, Sylvia Constante. Projetos e relatórios de pesquisa em administração. 3 ed. São Paulo: Atlas, 2004. 
Verzuh, Eric. MBA compacto, gestão de projetos. Rio de Janeiro: Campus, 2000.

Woiler, Samsão; Mathias, Washington Franco. Projetos, elaboração, análise. 2 ed. São Paulo: Atlas, 2008.

Yin, Robert. K. Estudo de Caso: planejamentos e métodos. 2 ed. Porto Alegre: Bookman, 2003.

Data do recebimento do artigo: 08/12/2011

Data do aceite de publicação: 14/02/2012

Revista de Gestão e Projetos - GeP, São Paulo, v. 3, n. 1, p 127-158, jan./abr. 2012. 